\title{
UM ESTUDO SOBRE O LOBBY EMPRESARIAL NA CÂMARA DOS DEPUTADOS (2007 A 2018)
}

\author{
Igor Sulaiman Said Felicio Borck ${ }^{1}$
}

\begin{abstract}
Resumo
Esse artigo tem como objetivo discutir o lobby empresarial realizado na Comissão de Desenvolvimento Econômico, Indústria, Comércio e Serviços (CDEICS) da Câmara dos Deputados, no período de 2007 a 2018. Procurou-se responder a seguinte questão de pesquisa, como as entidades empresariais realizam o lobby na CDEICS? As fontes utilizadas na pesquisa foram as notas taquigráficas das audiências públicas da CDEICS, onde encontra-se a transcrição das intervenções dos representantes empresariais convidados as audiências pelos parlamentares da comissão. A literatura de ciência política sobre empresariado e ação política indica a necessidade desses estudos para entender a força política do empresariado no regime democrático (Oliveira, 2003; Mancuso, 2004, 2007). Como hipótese de pesquisa estabeleceu-se que a organização política das entidades para o lobby resulta em uma ação coletiva eficiente do setor empresarial e que o lobby realizado por essas entidades na CDEICS contribui para uma taxa elevada de convergência entre a posição das entidades empresariais e produção legislativa federal (Mancuso, 2004). Os resultados preliminares dessa pesquisa indicam que o empresariado realiza um lobby intenso na CDEICS através de suas entidades representativas de classe: confederações, federações, associações setoriais e sindicatos, seja do setor industrial, financeiro ou agroexportador. Conclui-se que o lobby empresarial realizado na CDEICS pode influenciar na tomada de decisão dos parlamentares com relação aos projetos de lei em tramitação na Câmara dos Deputados que são de interesse da classe empresarial.
\end{abstract}

Palavras-chave: Empresariado; Câmara dos Deputados; Entidades Empresariais; lobby; Comissão de Desenvolvimento Econômico, Indústria, Comércio e Serviços (CDEICS).

\section{INTRODUÇÃO}

Esse artigo tem como objetivo discutir o lobby empresarial realizado na Comissão de Desenvolvimento Econômico, Indústria, Comércio e Serviços (CDEICS) da Câmara dos Deputados, no período de 2007 a 2018. Essa comissão é responsável por aprovar ou rejeitar todas as proposituras legislativas que tramitam na Câmara dos Deputados que envolvem os interesses diretos e indiretos dos segmentos empresariais brasileiros, organizados por meio de suas entidades representativas, como, por exemplo, a Confederação Nacional da Indústria (CNI), a Confederação Nacional da Agricultura (CNA) e a Federação Brasileira de Bancos (Febraban).

É na CDEICS que os parlamentares da Câmara dos Deputados colocam em pauta os projetos de lei que interferem nos interesses do capital privado nacional, e além disso, ouvem e discutem a posição das entidades empresariais envolvidas. A comissão se mostra fundamental para o empresariado realizar seu lobby, pois seus diretores e técnicos tem a oportunidade de fazer a

\footnotetext{
${ }^{1}$ Doutorando do Programa de Pós-Graduação em Ciência Política da Universidade Federal do Paraná (UFPR), e-mail: iborcki@hotmail.com e ORCID: https://orcid.org/0000-0001-8241-9128.
} 
sustentação oral de suas posições sobre os projetos de lei em tramitação na Câmara dos Deputados e consequentemente, tentar assim, influenciar o voto de cada parlamentar na comissão. A importância desses espaços de diálogo e discussão do Estado com o empresariado, como órgãos colegiados já foi verificada em trabalhos que procuraram entender como o empresariado ajuda a formular as políticas de desenvolvimento econômico junto ao Poder Executivo Federal, participando ativamente desses espaços políticos (SCHMITT 2018).

Todos os projetos de lei que tramitam na Câmara dos Deputados e que de alguma forma englobam temas sobre desenvolvimento econômico, indústria, comércio e serviços, são necessariamente discutidos pela CDEICS, sendo ela, uma das instâncias fundamentais para rejeitar ou dar continuidade a um projeto de lei nessa área, sendo assim, a CDEICS se torna uma arena política fundamental de disputa dos setores econômicos nacionais interessados em influenciar a política econômica nacional, pois nenhum projeto de lei sobre economia chega até o plenário de votação da Câmara - última instância de votação nessa casa legislativa - sem primeiro passar pela CDEICS.

Sabendo disso, a partir desse objeto, procurou-se responder a seguinte questão de pesquisa: como as entidades empresariais realizam o lobby na CDEICS? Dessa forma, a pesquisa se propõe a entender como esse lobby é realizado na Câmara dos Deputados, procurando por padrões de ação política do empresariado e formas de mensuração do lobby empresarial.

De certa maneira, dentro dessa linha, em análises futuras, também é possível comparar as expectativas do empresariado - suas demandas - com os resultados efetivos da tomada de decisão dos parlamentares, e assim verificar, a diferença entre expectativas do empresariado e os resultados legislativos concretos na Câmara dos Deputados, ou seja, a convergência entre as posições do empresariado e produção legislativa da CDEICS da Câmara dos Deputados.

Para responder ao problema de pesquisa, estabeleceu-se como hipótese que a organização política das entidades para o lobby resulta em uma ação coletiva eficiente do setor empresarial e que o lobby realizado por essas entidades na CDEICS contribui para uma taxa elevada de convergência entre a posição das entidades empresariais e produção legislativa federal (Mancuso, 2004).

A partir desse desenho de pesquisa, no primeiro capítulo desse artigo se discute como a literatura de ciência política tem tratando a força e fraqueza política do empresariado enquanto ator político ou grupo de pressão capaz de promover uma ação coletiva eficiente com relação aos seus interesses de classe frente as instituições políticas nacionais. No segundo capítulo é apresentado os resultados preliminares das primeiras análises das notas taquigráficas das audiências públicas da 
CDEICS da Câmara dos Deputados do período de 2007 a 2018, bem como, é apresentado algumas características de como o empresariado participa das reuniões da comissão de maneira ativa, buscando promover seu lobby nos espaços destinados à sua participação política através da sustentação oral de suas posições na condição de convidado da comissão.

Por fim nas considerações finais é apresentada a discussão de como essa análise preliminar permite concluir que que o lobby empresarial realizado na CDEICS pode influenciar na tomada de decisão dos parlamentares com relação aos projetos de lei em tramitação na Câmara dos Deputados que são de interesse da classe empresarial.

\section{LOBBY EMPRESARIAL NA LITERATURA DE CIÊNCIA POLÍTICA}

O campo de pesquisa na área de empresariado e o regime democrático é amplo, e merece especial atenção à pluralidade de análises. Existem diversas formas de organizar esses trabalhos, uma delas foi feita por Mancuso (2007), onde o autor apresenta "ondas interpretativas" sobre a força ou fraqueza política do empresariado na literatura de ciência política sobre o tema.

Segundo Mancuso (2007) a "primeira onda interpretativa" sobre a força política do empresariado se desenvolveu na década de 1950 até a primeira metade da década de 1960, e buscou apresentar a ideia de que a "parcela nacionalista do empresariado industrial brasileiro de grande porte era capaz de liderar uma aliança com os trabalhadores pela revolução nacional e democrática, contra os interesses arcaicos do latifúndio (no plano interno) e do imperialismo (no plano externo)”, os principais trabalhos expoentes dessas teorias foram o de Hélio Jaguaribe Gomes de Mattos (1958) e Nelson Werneck Sodré (1958), que apostavam no empresariado como um ator político forte diante do cenário político nacional, capaz de cumprir sua missão de classe modernizadora do Estado e da sociedade.

Porém na "segunda onda interpretativa", que se desenvolveu nas décadas de 1960 e 1970, com os trabalhos de Fernando Henrique Cardoso (1963; 1971; 1972), Celso Furtado (1965), Caio Prado Júnior (1966), Luciano Martins (1968), Luiz Carlos Bresser-Pereira (1974) e Florestan Fernandes (1976), apresentaram algumas ideias contrárias a "primeira onda", e disseram que a “burguesia" brasileira era incapaz de cumprir sua missão na "revolução nacional e democrática", pois se recusava em realizar uma aliança política com a classe trabalhadora, e que não se opunha ao latifúndio, e também não era nacionalista e anti-imperialista, requisitos necessários para uma grande transformação nas relações políticas da época. Nesse sentido esses autores da "segunda onda 
interpretativa", desenharam o empresariado com um ator político fraco, que estava longe de sua missão enquanto classe social.

Já a "terceira onda interpretativa", que se desenvolveu na segunda metade da década de 1970, década de 1980, e primeira metade da década de 1990, se contrapôs a "segunda onda" e demostrou como o empresariado era mais forte do que se pensava, e isso ocorreu principalmente quando o empresariado decide romper com o "bloco que subiu ao poder com o golpe de 1964", participando da campanha contra a estatização e a campanha pela redemocratização, e além disso, sendo de certa forma, protagonista - apesar de todos os problemas - do processo de industrialização, tanto no Estado Novo, quanto no Ditadura Militar, e fez isso, através de suas entidades de classe do sistema corporativo, dos "anéis burocráticos" e dos contatos pessoais diretos com os tomadores de decisão. Os principais trabalhos expoentes dessas teorias foram Sebastião Velasco e Cruz (1978), Leigh Payne (1994), Eli Diniz e Renato Boschi (1978), Maria Antonieta Leopoldi (1984) e René Dreifuss (1981; 1989).

$\mathrm{Na}$ "quarta onda interpretativa" encontramos trabalhos que buscaram resgatar a ideia de que o empresariado era fraco, isso porque não conseguia promover ação coletiva unificada, tanto no âmbito setorial quanto no inter-setorial. Segundo os autores dessa onda, essas dificuldades de promover ação coletiva são fruto do sistema de corporativista de representação de interesses, que impediam o empresariado de exercer um papel protagonismo político, porque "engendram entidades setoriais de grau superior, cujos líderes não são representativos e porque não preveem uma entidade de cúpula multisetorial". Os principais trabalhos expoentes dessas teorias foram de Ben Ross Schneider (1977a; 1997b; 1998; 2002; 2004), Kurt Weyland (1998a; 1998b; 2001), Timothy Power e Mahrulkh Doctor (2002).

Já na "quinta e última onda interpretativa", encontramos o resgate da ideia de que o empresariado é forte politicamente, mostrando que apesar dos empecilhos do sistema corporativista, o empresariado realizou um grande esforço de organização e mobilização política, que culminou por exemplo na consolidação da Confederação Nacional da Indústria (CNI), como um entidade de cúpula do sistema corporativista de representação de interesses, que se mostrou capaz de "decidir por conta própria", e consequentemente "assumir o custo necessário para deflagrar e organizar a ação coletiva, com vistas à benefícios coletivos”. (MANCUSO, 2007, p. 137). Os principais trabalhos expoentes dessas teorias são de Amâncio Jorge de Oliveira (2003), Wagner Pralon Mancuso (2004; 2007), e Amâncio Jorge de Oliveira e Wagner Pralon Mancuso (2006). 
É justamente nessa quinta onda que esse artigo se insere, ou seja, busca entender como a CNI, e outras entidades empresariais, atuam como entidades de cúpula, na representação de interesses de seus associados perante a Comissão de Desenvolvimento Econômico, Indústria, Comércio e Serviços (CDEICS) da Câmara dos Deputados, para influenciar os tomadores de decisão no sentido de atender as suas demandas de classe empresarial.

Mancuso (2004) argumenta a importância dessas pesquisas, dizendo que a indústria brasileira, organizada através da CNI realiza intenso esforço de pressão política, ou seja, se articula politicamente para influenciar o parlamento através de seus instrumentos de pressão política, as entidades empresariais. Dessa maneira, as entidades procuram influenciar os tomadores de decisão, no caso em específico, os parlamentares do Congresso Nacional para votarem de acordo com suas expectativas e demandas.

Esse tipo de pressão política ocorre em diversos estágios do processo legislativo federal, desde da apresentação da propositura, bem como sua discussão nas comissões e na votação no plenário das casas legislativas. Conforme escreve Mancuso (2004), “A pressão política pode ocorrer em diversos estágios da produção legislativa: no estágio de discussão dos projetos nas duas Casas do Congresso Nacional, no de votação dos projetos nas comissões ou no plenário, no da sanção (ou veto) presidencial, ou ainda no estágio da votação pelos parlamentares de eventuais vetos do presidente" (MANCUSO, 2004, p. 517). Por isso a necessidade de estudos voltados a atuação política (lobby) do empresariado brasileiro perante o Estado e suas instituições.

Outras pesquisas também apontam a necessidade do estudo do lobby empresarial no Congresso Nacional, com foco nas estruturas internas das entidades empresariais, como por exemplo o Conselho de Assuntos Legislativos (COAL) e a Gerência de Assuntos Legislativos (GEAL) da CNI, que pressionam os parlamentares, através de especialistas em lobby contratados para fazer valer seus interesses no Congresso Nacional (SANTOS 2011).

Essa atuação foi percebida em outros trabalhos, como os que mostraram que existem três polos de influência sobre o Congresso Nacional no Brasil (ARAGÃO, 1996), sendo um deles o próprio Executivo Federal, o segundo a classe trabalhadora e o terceiro o empresariado. O terceiro polo de influência sobre o Congresso Nacional, formou-se no final da década de 1990 e início dos anos 2000, uma coalizão conhecida como "ação empresarial” que buscava pressionar o Congresso Nacional entorno de seus interesses de classe, conseguindo incentivos fiscais para melhorar a competitividade do setor. 
Esses trabalhos demostram que os empresários se organizam a fim de produzir ganhos coletivos para o segmento industrial, mostrando que a tese da debilidade política do empresariado, apresentado pela "quarta onda interpretativa" discutida por Mancuso (2007), não se confirma no Brasil. Mas de qualquer maneira, essas teorias da debilidade política do empresariado, reforçam a necessidade de estudos sobre a força política do lobby empresarial, pois confirmam que o empresariado é um importante ator político no cenário nacional e deve ser pesquisado, e este é intuito do próximo capítulo, apresentar os resultados iniciais da pesquisa sobre o lobby empresarial na Comissão de Desenvolvimento Econômico, Indústria, Comércio e Serviços (CDEICS) da Câmara dos Deputados do período de 2007 a 2018.

\section{LOBBY EMPRESARIAL NA COMISSÃO DE DESENVOLVIMENTO ECONÔMICO, INDÚSTRIA, COMÉRCIO E SERVIÇOS DA CÂMARA DOS DEPUTADOS}

A análise do lobby na CDEICS começa com análise das notas taquigráficas do período de 2007 a 2018, disponibilizadas no site da comissão². As notas taquigráficas consistem na transcrição das audiências públicas da comissão, onde é descrito, com detalhes, a discussão realizada por cada parlamentar membro ou convidado da comissão. Portanto o material empírico completo, ou seja, o corpus da pesquisa, totaliza quarenta e nove notas taquigráficas de audiências públicas da CDEICS no período recortado.

A análise inicial das notas taquigráficas forneceu alguns resultados preliminares sobre o lobby empresarial. Já foi possível verificar que todos os segmentos empresariais participam dos debates das audiências públicas da comissão, tanto o setor industrial, quanto do financeiro e do agroexportador. É importante salientar que são nas audiências públicas dessa comissão que o empresariado, por meio de suas entidades, defende suas posições políticas, no sentido de pressionar os parlamentares, através de argumentos técnicos e políticos a votarem de acordo com suas expectativas de classe.

Verificou-se que das 49 audiências analisadas, o empresariado participou de 34, 69,4\% do total analisado. Das 49 audiências, 4 delas foram realizadas também com a presença da classe trabalhadora através de suas entidades sindicais. Esse dado indica que o empresariado participa de

\footnotetext{
${ }^{2}$ Site da CDEICS: https://www2.camara.leg.br/atividade-legislativa/comissoes/comissoes-permanentes/cdeic, acessado em 24 de junho de 2020.
} 
maneira ativa das audiências públicas, mais do que outros segmentos envolvidos, como os trabalhadores, por exemplo que participaram de apenas 8,2\% das audiências analisadas nesse período.

O empresariado procura nessa comissão fazer sustentação oral de suas posições favoráveis ou contrárias com relação aos projetos e temáticas debatidas pelos parlamentares membros da CDEICS, futuramente pode-se cruzar os dados da posição do empresariado defendida nessas sustentações orais com o resultado efetivo da votação dos projetos de lei na comissão, para se aferir uma taxa de convergência entre o que foi defendido pelo empresariado e o que realmente a comissão votou, isso ajudaria a entender se o lobby realizado na comissão é bem ou mal sucedido, conforme será melhor discutido nas considerações finais desse artigo.

Alguns exemplos dessa participação ativa podem ser verificados, por exemplo, na audiência pública da CDEICS, realizada em 2007, com a temática: “Crise no Setor Coureiro-Calçadista”, que contou com a presença de Caetano Bianco Neto, Presidente do Sindicato das Indústrias de Calçados de Jaú, Ivanor Pedro Ferreira, Secretário da Associação das Micro e Pequenas Empresas de Sapiranga, Jorge Faccioni, Vice-Presidente da Associação Comercial, Industrial e de Serviços de Novo Hamburgo, Campo Bom e Estância Velha (ACI-NH/CB/EV), Wayner Machado Silva, VicePresidente do Centro das Indústrias de Curtumes do Brasil (CICB), Paulo Griebeler, DiretorExecutivo da Associação das Indústrias de Curtume do Rio Grande do Sul (AICSul), Roberto Müller, Presidente do Sindicato dos Trabalhadores nas Indústrias Calçadistas de Teutônia (SITICALTE) e Milton Cardoso, Vice-Presidente da Associação Brasileira das Indústrias de Calçados (ABICALÇADOS). Essa audiência pública de 2007 é um exemplo de como a comissão também funciona como mediadora dos interesses não só do empresariado, mas da classe trabalhadora, que mesmo com participação reduzida, ainda assim se faz presente para o debate, junto com o empresariado e com os parlamentares, como pode ser verificado nas entidades convidadas pela comissão para essa audiência.

Outro exemplo é a audiência pública de 2014, sob a temática: "Discussão sobre a ampliação do mercado livre de energia elétrica" que contou com a presença de Luiz Roberto Morgenstern Ferreira, Consultor da Associação Brasileira dos Produtores Independentes de Energia Elétrica (APINE) e Reginaldo Almeida De Medeiros, Presidente-Executivo da Associação Brasileira dos Comercializadores de Energia (ABRACEEL), notemos que nesse caso a audiência ocorre sem a presença de trabalhadores, como na grande maioria das audiências analisadas, além disso essa audiência é um bom exemplo de como, tanto, dirigentes empresariais, na figura do Sr. Reginaldo 
Almeida De Medeiros, quanto, técnicos especializados em lobby empresarial, na figura do com o Sr.

Luiz Roberto Morgenstern Ferreira, participam desses espaços de defesa de posições.

Outra audiência pública, realizada em 2012, com o tema: "Debate sobre atividades dos caixas de supermercado" é um exemplo de raros casos, onde somente a classe trabalhadora participa através também de suas entidades, e isso geralmente acorre quando a temática é muito específica sobre condições e relações de trabalho. Essa audiência, por exemplo, contou com a presença de José Augusto da Silva Filho, Coordenador Nacional do Fórum Sindical dos Trabalhadores (FST), Vicente Da Silva, Vice-Presidente da Confederação Nacional dos Trabalhadores do Comércio (CNTC), Alci Matos Araújo, Presidente da Confederação Nacional dos Trabalhadores do Comércio (CONTRACS/CUT), José Marçal Jackson Filho, Pesquisador Titular da Fundação Jorge Duprat Figueiredo de Segurança e Medicina do Trabalho (FUNDACENTRO), Maurício Lucena do Val, Diretor de Políticas de Comércio e Serviços da Secretaria de Comércio e Serviços do Ministério do Desenvolvimento, Indústria e Comércio Exterior (MDIC). É importante notar que nessa audiência também participa um representante do poder executivo, que procura trazer para mesa de discussões a posição do governo acerca do tema debatido, isso reforça a ideia de a comissão ser um importante espaço institucional de debate e mediação entre as demandas da sociedade civil organizada e o Estado. Parece que o empresariado compreende bem essa relação e busca ao máximo se organizar através de suas entidades para participar da CDEICS e disputar politicamente esse espaço.

Em outra audiência pública analisada, verificou-se também que as audiências podem ter temas mais específicos, como o debate sobre projetos de lei e programas, o que ocorreu em 2018, quando o Deputado Otávio Leite (PSDB-RJ), também presidente da comissão à época, propôs a discussão do Programa Nacional de Microcrédito Produtivo Orientado (PNMPO), programa que foi objeto da Lei $\mathrm{n}^{\mathrm{o}} 13.636$, de 2018 .

Nesta audiência se fez presente Luiz Henrique Machado, Assessor Especial de Controle Interno Substituto do Ministério do Trabalho, Marcelo Porteiro Cardoso, Superintendente do Banco Nacional de Desenvolvimento Econômico e Social (BNDES), Marcos Antônio Ventura de Oliveira, Coordenador do Grupo de Trabalho da Federação Brasileira dos Bancos (FEBRABAN), Tarcísio Foster Gerotto, Gerente de Divisão da Diretoria de Governo do Banco do Brasil, Tatiana Cristina Barbosa da Silva, Gerente de Clientes e Negócios da Gerência Nacional de Estratégia de Micro e Pequeno Empreendedorismo da Caixa Econômica Federal e Cleofas Salviano Júnior, Consultor do Departamento de Regulação do Sistema Financeiro do Banco Central do Brasil (BACEN). 
Fica evidente na composição dos convidados da audiência pública de 2018 que a temática foi debatida somente pelos parlamentares da comissão, pelos representantes do poder executivo federal, das agências estatais e o empresariado do segmento financeiro do capital privado nacional, representados pela Federação Brasileira dos Bancos (FEBRABAN), demonstrando a importância que dão os parlamentares da comissão ao empresariado financeiro em detrimento de tantas outras entidades de classe interessadas na discussão, que não são chamadas a mesa, como as entidades trabalhistas e outros segmentos organizados da sociedade civil.

Outras audiências analisadas mostraram que por vezes o empresariado optar por enviar técnicos ao invés de líderes empresariais das entidades (Diretores) para fazer as sustentações orais na condição de convidado da CDEICS, como foi o caso da audiência de 2014, com o tema: "Seminário: O Panorama da Economia Brasileira" que contou com a presença de Guilherme Afif Domingos, Ministro de Estado, Chefe da Secretaria da Micro e Pequena Empresa da Presidência da República, Marcelo De Ávila, Assessor Técnico da Confederação da Agricultura e Pecuária do Brasil (CNA), Renato Da Fonseca, Gerente Executivo de Pesquisa e Competitividade da Confederação Nacional da Indústria (CNI), Roberto Nogueira Ferreira, Consultor da Presidência da Confederação Nacional do Comércio de Bens, Serviços e Turismo (CNC), Mauro Borges, Ministro de Estado do Desenvolvimento, Indústria e Comércio Exterior.

Esses e outros exemplos analisados de audiências públicas da comissão, reforçam a ideia de que o empresariado - dos mais diversos segmentos econômicos - participa ativamente na CDEICS e que isso se dá através de suas entidades representativas de classe. Fica nítido também, que o empresariado participa dessa comissão mais do que os outros segmentos da sociedade civil organizada, e que utiliza esse espaço para realizar seu lobby político, ou seja, o usa, na defesa de seus interesses, e assim o faz, na tentativa de influenciar a votação dos parlamentares da comissão.

Outro resultado preliminar importante dessa pesquisa é que a comissão se apresenta, conforme mostra dados, como um espaço de debate das questões nacionais sobre desenvolvimento econômico, reconhecida como uma etapa importante do processo legislativo pelo empresariado, que de maneira ativa participa de suas audiências, pois a pesquisa mostrou que das 49 audiências públicas da CDEICS realizadas entre 2007 a 2018, o empresariado participou de 69,4\% delas, indicando que o empresariado e suas entidades valorizam esse espaço político, e mais do que isso, que acreditam que é fundamental participar, se fosse diferente, participariam menos e com menor representação de líderes empresariais das entidades empresariais. 


\section{CONSIDERAÇÕES FINAIS}

A pesquisa demostrou como o empresariado brasileiro - dos mais diversos segmentos econômicos - organizado através de suas entidades representativas de classe: as confederações, federações, associações nacionais e sindicatos, praticam um lobby intenso na CDEICS da Câmara dos Deputados, no período de 2007 a 2018. Se faz necessário ressaltar que a pesquisa compreende o lobby político empresarial, como toda e qualquer ação do capital privado nacional - organizado politicamente através de entidades representativas de classe - que vise influenciar na tomada de decisão política do agente estatal sobre as políticas nacionais de desenvolvimento econômico.

Os resultados também indicam que o empresariado participa mais da CDEICS da Câmara dos Deputados do que outros segmentos da sociedade civil organizada, ou seja, outros grupos de pressão, como os trabalhadores, por exemplo, isso não significa que os trabalhadores sejam menos interessados nas políticas nacionais de desenvolvimento econômico, pelo contrário, isso significa que o empresariado através de suas entidades é melhor articulado politicamente e consegue ser mais acionado pelos parlamentares da comissão na condição de convidado em contraste com a articulação dos trabalhadores através de suas entidade de classe.

A literatura de ciência política (MANCUSO 2007) aponta a necessidade da criação de formas mais eficientes de mensuração do lobby empresarial, no sentido de entender se o empresariado é forte ou fraco politicamente em sua ação coletiva frente as instituições políticas nacionais, ou ainda, se realmente consegue realizar uma ação coletiva eficiente e coesa, onde fique demostrado que sua pressão ou influencia conseguiu obter resultados positivos para sua classe. Por isso, a partir desses resultados preliminares de pesquisa, pretende-se cruzar as informações do lobby empresarial na CDEICS e os resultados efetivos das votações da comissão, para que assim possamos começar a pensar em mensurar uma taxa de convergência entre as posições dos empresários e o resultado efetivo do processo legislativo nessa comissão. Esse será o próximo passo da pesquisa.

\section{REFERENCIAS}

ARAGÃO, Murillo. A ação dos grupos de pressão nos processos constitucionais recentes no Brasil. Revista de Sociologia e Política, n. 06-07, p. 149-165, 1996.

BRESSER-PEREIRA, Luiz Carlos. Empresários e administradores no Brasil. São Paulo: Editora Brasilience, 1974. 
CARDOSO, Fernando Henrique. Autoritarismo e democratização. Rio de Janeiro: Paz e Terra, 1975.

CARDOSO, Fernando Henrique. Empresário industrial e desenvolvimento econômico no Brasil. São Paulo: Difusão Europeia do Livro, 1972.

CARDOSO, Fernando Henrique. Hegemonia burguesa e independência econômica: raízes estruturais da crise política brasileira.1965. In: FURTADO, Celso. (org.). Brasil: tempos modernos. Rio de Janeiro: Civilização Brasileira, 1968

CARDOSO, Fernando Henrique. Política e desenvolvimento em sociedades dependentes: ideologias do empresariado industrial argentino e brasileiro. Rio de Janeiro: Zahar Editores, 1971.

DINIZ, Eli. Neoliberalismo e corporativismo: as duas faces do capitalismo industrial no Brasil. Revista Brasileira de Ciências Sociais, v. 7, n. 20, p. 31-46, 1992.

DINIZ, Eli; BOSCHI, Renato Raul. Empresariado nacional e Estado no Brasil. Rio de Janeiro: Forense-Universitária, 1978.

DINIZ, Eli; BOSCHI, Renato. Autonomia e dependência na representação de interesses industriais1. Rio de Janeiro: Estado e Sociedade, p. 111, 2016.

DINIZ, Eli; BOSCHI, Renato. O Legislativo como arena de interesses organizados: a atuação dos lobbies empresariais. Locus-Revista de História, v. 5, n. 1, 1999.

DINIZ, Eli; BOSCHI, Renato; SANTOS, Fabiano. Lideranças empresariais e problemas da estratégia liberal no Brasil. Rio de Janeiro: Revista Brasileira de Ciências Sociais, n. 23, 1992.

DOCTOR, Mahrukh. Business and delays in port reform in Brazil. Brazilian Journal of Political Economy, v. 22, n. 2, 2002.

DREIFUSS, René A. 1964: A Conquista do Estado-Ação Política. Poder e Golpe de Classe. Petrópolis: Editora Vozes, 1981.

DREIFUSS, René Armand. O jogo da direita na Nova República. Petrópolis: Vozes, 1989.

FERNANDES, Florestan. A Revolução Burguesa no Brasil: ensaio de interpretação sociológica. Rio de Janeiro: Zahar, 1976.

FURTADO, Celso. Obstáculos políticos ao crescimento econômico no Brasil. Revista Civilização Brasileira, Rio de Janeiro, v. 1, n. 1, 1971.

LEOPOLDI, Maria Antonieta Parahyba. Industrial associations and politics in contemporary Brazil. Tese de Doutorado em Ciência Política. University of Oxford, 1984.

MANCUSO, Wagner Pralon. O empresariado como ator político no Brasil: balanço da literatura e agenda de pesquisa. Curitiba: Revista de Sociologia e Política, n. 28, p. 131-146, 2007. 
MANCUSO, Wagner Pralon. O lobby da indústria no Congresso Nacional: empresariado e política no Brasil contemporâneo. Rio de Janeiro: Dados, v. 47, n. 3, p. 505-547, 2004.

MARTINS, Luciano. Industrialização, burguesia nacional e desenvolvimento: introdução à crise brasileira. Rio de Janeiro: Ed. Saga, 1968.

MATTOS, Hélio Jaguaribe Gomes. O problema do desenvolvimento econômico e a burguesia nacional. São Paulo: Federação das Indústrias do Estado de São Paulo, 1958.

OLIVEIRA, Amâncio Jorge Silva Nunes. O papel da coalizão empresarial brasileira e as negociações da ALCA. Tese de Doutorado em Ciência Política. Universidade de São Paulo. 2004.

PAYNE, Leigh. Brazilian industrialists and democratic change. Johns Hopkins University Press, 1994.

POWER, Timothy Joseph; DOCTOR, Mahrukh. The resilience of corporatism: continuity and change in Brazilian corporatist structures. Centro de Estudos Brasileiros, University of Oxford, 2002.

PRADO JÚNIOR, Caio. A Revolução Brasileira. São Paulo: Brasiliense, 1966.

SANTOS, Manoel Leonardo Wanderley Duarte. O parlamento sob influência: o lobby da indústria na Câmara dos Deputados. Recife, Pernambuco, Brasil. Tese de Doutorado em Ciência Política. Universidade Federal do Pernambuco. 2011.

SCHMITT, Stefanie Tomé. The Complex Interlinking Network of Business Access. Trabalho apresentado no XXXVI Congresso Internacional da Associação Latino-Americana de Estudos (LASA), Barcelone, Espanha, 2018.

SODRÉ, Nelson Werneck. O problema da burguesia. Introdução à revolução brasileira, Rio de Janeiro: J. Olympio. 1958. 